\title{
What information is being acquired during the period of Quiet Eye? Comment on Vickers
}

\author{
Sérgio T. Rodrigues ${ }^{1, *}$ \& Martina Navarro ${ }^{2,3}$ \\ 1 Department of Physical Education, State University of São Paulo, Bauru, SP, Brazil \\ 2 Department of Ophthalmology, Federal University of São Paulo, São Paulo, SP, Brazil \\ 3 Department of Physical Education, University Cruzeiro do Sul, São Paulo, SP, Brazil \\ * Corresponding author: Department of Physical Education, State University of São Paulo (UNESP), Av. Eng. Luis Edmundo Carrijo Coube, 14-01 - \\ CEP: 17033-360, Bauru, SP, Brazil, Tel: +55 14 31036082, Fax: +55 1431036071 \\ Email: srodrigu@fc.unesp.br
}

\section{TA COMMENTARY}

\section{Article History:}

Received $16^{\text {th }}$ May 2016

Accepted $5^{\text {th }}$ June 2016

Published $13^{\text {th }}$ October 2016

Handling Editor:

Ernst-Joachim Hossner

University of Bern, Switzerland

Editor-in-Chief:

Martin Kopp

University of Innsbruck, Austria

\begin{abstract}
Sports and athletes' highest performance offer a fascinating scenario to investigate perceptual-motor expertise. The remarkable work of Joan Vickers has captured this opportunity and built a valuable experimental paradigm. Our commentary emphasizes what information is being acquired during the period of Quiet Eye (QE), capable to produce successful performance. First, an extended notion of visual system that includes posture is presented. It is suggested that QE would represent a collective postural effort (resulting from movements of eyes, head, trunk, and whole body) to acquire the relevant information available in the optic flow. Second, the contribution of neural structures and functioning for vision and attention is discussed. Models of neural networks of attention and two visual systems are described with respect to QE and some questions about action parameters and motor programs are raised.
\end{abstract}

Keywords:

Quiet Eye - information acquisition - posture - attention - neural networks

Citation:

Rodrigues, S. T., \& Navarro, M. (2016). What information is being acquired during the period of Quiet Eye? Comment on Vickers. Current Issues in Sport Science, 1:112. doi: 10.36950/CISS_2016.112

This is a commentary on a CISS target article authored by Joan N. Vickers. For retrieving the whole target article including index of contents, editorial, main article, all peer commentaries and author's response:

Hossner, E.-J. (Ed.) (2016). Quiet Eye research - Joan Vickers on target. Current Issues in Sport Science, 1:100. doi: 10.15203/CISS_2016.100

\section{Introduction}

Sports and athletes' highest performance offer a fascinating scenario to investigate perceptual-motor expertise. The remarkable work of Joan Vickers has captured this opportunity and built a valuable experimental paradigm. Since its original proposal 20 years ago (Vickers, 1996), research on the phenomenon of Quiet Eye (QE) has evolved consistently, offering a cognitive approach to the success of motor skills based primarily on eye movements data. Vickers (2016) showed that QE has become a comprehensive topic of research, covering the following aspects: differences between expert and non-expert (near-expert, intermediate or novice) athletes, targeting and interceptive actions, training for QE enhancement, child devel- opment and pressure or anxiety situations. Additionally, a more precise identification of neural networks related to QE is offering a complementary interpretation and convincing generalization regarding this topic.

QE occurs when gaze is relatively stationary on a location or moving object (according to a maximum $3^{\circ}$ of visual angle and minimum $100 \mathrm{~ms}$ criterion) prior to movement initiation. QE is expected to facilitate information processing; its duration reflects the time needed to program and fine-tune a response; long durations of QE extend the period of critical preparation, which involves response selection and the fine tuning of movement parameters for motor programming (Gonzalez, Causer, Miall, Grey, Humphreys, \& Williams, 2015). During this period, it is argued that "task-specific spatial information" (Vickers, 2016, 
p. 7) is acquired to accomplish the definition of motor program parameters, with the goal-directed, dorsal attention network (DAN) being responsible for focusing and sustaining attention to relevant cues at particular locations, and the stimulusdriven, ventral attention network (VAN) encoding memories and controlling movement-related emotions (Corbetta, Patel, \& Shulman, 2008). As a result of practice and expertise, DAN is thought to block or suppress distraction or anxiety-generated stimuli that may arrive from the VAN system (Gonzalez et al., 2015; Vickers, 2016).

We have organized our comments to emphasize what information is being acquired during the period of $\mathrm{QE}$, capable to produce successful performance. Furthermore, an extended notion of the visual system is discussed, including posture as well as the contribution of neural models of vision and attention.

\section{Posture supporting QE}

We would like to discuss how gaze behavior may be associated with balance control as well as theoretical aspects involved in this relation. Other perspectives, as alternative to the information processing approach proposed by Vickers (1996, 2016), could add new elements to QE analysis. Not just the visual search pattern itself, but how experts can make use of the obtained information is crucial to understanding expertise and talent development (Savelsbergh, Haans, Kooijman, \& van Kampen, 2010). A perception-action perspective suggests that movement control is based on a continuous coupling to available perceptual information, which is presumed to evolve over time (Savelsbergh \& van der Kamp, 2000; Savelsbergh, Onrust, Rouwenhorst, \& van der Kamp, 2006). For instance, the Gibsonian notion of visual system ("eyes-in-the-head-on-the-bodyresting-on-the-ground"; Gibson, 1979, p. 205) favors the simultaneous consideration of gaze and postural data during motor actions.

Continuous and predictable saccadic and smooth pursuit eye movements improve postural stabilization during quiet stance (Aguiar et al., 2015; Rodrigues et al., 2013; Rodrigues et al., 2015); in more dynamical contexts, increased postural stability due to motor learning has been reported in a variety of motor skills, such as rifle shooting (Era, Konttinen, Mehto, Saarela, \& Lyytinen, 1996) and manual rhythmic movements (Amado, Palmer, Hamill, \& van Emmerik, 2016). Interestingly, expertise of ball cascade jugglers seems associated with parsimonious oculomotor and attention pattern ("gaze-through" strategy) with fixations at the scene's central location, weaker frequency locking between point-of-gaze and ball movements, reduced dependency to visually tracking ball motion, and improved anterior-posterior body sway stabilization (Dessing, Rey, \& Beek, 2012; Huys \& Beek, 2002; Huys, Daffertshofer, \& Beek, 2004; Rodrigues et al., 2016), which is in line with experts' higher capability of decoupling postural control and arm movements (Amado et al., 2016).

Considering that postural adjustments seem to support opti- mal gaze behavior during complex actions, QE could be interpreted as a period of extraction of relevant visual information (e.g., time-to-contact variables; Lee, 1998, 2009) from optic flow. Although optic flow results from translational components of head movements in space and eye movements add rotational components to the flow on the retina (Cutting, 1996; Kim, Growney \& Turvey, 1996; Kim, Turvey \& Growney, 1996), a process of minimization of rotational consequences to the flow, called gaze stabilization (Daniel \& Lee, 1990), seems advantageous to optimizing translational information acquisition with respect to the perceiver. As human visual input depends on the dynamics of all body parts, QE is constrained by posture. On the other hand, QE would represent this collective postural effort (resulting from movements of eyes, head, trunk, and whole body) to acquire the relevant information available in the optic flow, needed to successful performance.

\section{Brain, vision, attention, and QE}

To analyze the role of brain functioning in perception and action, we would like to briefly discuss models regarding processes of vision and attention. As shown above, Vickers (2016) emphasized the neural bases of attention, referring to functions of DAN and VAN (Corbetta et al., 2008). Also based upon neurological evidence, Milner and Goodale $(1995,2008)$ proposed a model of two visual systems, advancing from previous work (Livingstone \& Hubel, 1988; Schneider, 1969; Trevarthen, 1968; Ungerleider \& Mishkin, 1982). This model posits a separate ventral visual system for the purposes of object perception and representation in space and a second dorsal system, which uses this visual information in formulating an effective response. Visual inputs of each system are transformed for different purposes - one for representing visual information and another for using vision to guide action (Milner \& Goodale, 2008). Despite the apparent independence of the two streams, coordinated action is dependent upon a high degree of cooperation between the two pathways, with enhanced attentional activity probably around movement initiation (Milner \& Goodale, 1995); the transfer of high-level visual information between the two streams probably occurs in an early stage of this process. A first prerequisite of an action is selecting a goal object to be addressed, when the object is "flagged" due to enhanced attention, during processing by the ventral stream; a second prerequisite is to convey whatever "top-down" knowledge about the object is needed to supplement the "bottomup" sensory information used by the dorsal stream (Milner \& Goodale, 1995).

According to this general view, QE period would be under control of the ventral vision-for-perception system, mentally representing environmental information, and the motor action would be regulated by the dorsal vision-for-action system, within the three-dimensional space. For example, in a table tennis forehand stroke task, participants visually tracked the ball (QE) and stabilized eye and head around the time of ball-bat 
contact; Milner and Goodale's model accommodate evidence from both early information acquisition to predict a ball's future trajectory and action planning, and late movement adjustments based on image expansion information (Rodrigues, Vickers, \& Williams, 2002).

Models of both Milner and Goodale (2008) and Corbeta et al. (2008) characterize visual and attentional processing in the brain, which results in perceptuo-motor behaviors, such as QE. Although we acknowledge the importance of combining neuroimaging (event related potentials, transcranial magnetic stimulation, functional magnetic resonance imaging) and other technologies to better explain the links between gaze and performance in future studies (Corbetta et al., 2008), data from investigations on neural networks and perceptuo-motor behavior represent distinct levels of analysis. Yet, knowledge on neural structure with respect to $Q E$ is important and welcome; it does not necessarily imply improvement of QE explanatory power. For instance, the referred models do not describe the information content obtained during QE which generates successful performance.

The use of a more detailed description of neural structures underlying the QE by Vickers (2016), emphasizing the role of attention during the process of information acquisition to action control, has left some open questions. How are these attention networks connected to the process of providing parameters to a motor program? How does the better understanding on these neural structures affect the rationale of setting parameters for a motor program during $\mathrm{QE}$, originally presented by Vickers (1996)? The "GPS"-like (Vickers, 2016, p. 8), optimal spatial representation, supposedly acquired during $\mathrm{QE}$, should feed the motor program to be subsequently triggered; however, the notion of motor program was replaced by the term "brain" in the present version of QE perspective. Which are the theoretical consequences of this change?

\section{Funding}

The research described in this paper was funded by the Conselho Nacional de Desenvolvimento Científico e TecnológicoCNPq (Process: 458916/2014-5) to the first author, and by the Fundação de Amparo à Pesquisa do Estado de São PauloFAPESP (Process: 2013/09855-9) to the second author.

\section{Competing Interests}

The authors have declared that no competing interests exist.

\section{Data Availability Statement}

All relevant data are within the paper.

\section{References}

Aguiar, S. A., Polastri, P. F., Godoi, D., Moraes, R., Barela, J. A., \& Rodrigues, S. T. (2015). Effects of saccadic eye movements on postural control in older adults. Psychology \& Neuroscience, 8, 19-27.

Amado, A. C., Palmer, C. J., Hamill, J., \& van Emmerik, R. E. A. (2016). Coupling of postural and manual tasks in expert performers. Human Movement Science, 46, 251-260.

Corbetta, M., Patel, G., \& Shulman, G. L. (2008). The reorienting system of the human brain: From environment to theory of mind. Neuron, 58, 306-324. doi: 10.1016/j.neuron.2008.04.017

Cutting, J. E. (1996). Wayfinding from multiple sources of local information in retinal flow. Journal of Experimental Psychology: Human Perception and Performance, 22, 1299-1313. doi: 10.1037/0096-1523.22.5.1299

Daniel, B. M., \& Lee, D. N. (1990). Development of looking with head and eyes. Journal of Experimental Child Psychology, 50, 200-216.

Dessing, J. C., Rey, F. P., \& Beek, P. J. (2012). Gaze fixation improves the stability of expert juggling. Experimental Brain Research, 216, 635-644. doi: 10.1007/s00221-011-2967-6

Era, P., Konttinen, N., Mehto, P., Saarela, P., \& Lyytinen, H. (1996). Postural stability and skilled performance. A study on top-level and naive rifle shooters. Journal of Biomechanics, 29, 301-306. doi: 10.1016/0021-9290(95)00066-6

Gibson, J. J. (1979). The ecological approach to visual perception. Boston: Houghton Mifflin.

Gonzalez, C. C., Causer, J., Miall, R. C., Grey, M. J., Humphreys, G., \& Williams, A. M. (2015). Identifying the causal mechanisms of the quiet eye. European Journal of Sport Science, Epub ahead of print. doi: 10.1080/17461391.2015.1075595

Huys, R., \& Beek, P. J. (2002). The coupling between point-of-gaze and ball movements in 20 three-ball cascade juggling: The effects of expertise, pattern and tempo. Journal of Sports Sciences, 20, 171-186.

Huys, R., Daffertshofer, A., \& Beek, P .J. (2004). Multiple time scales and multiform dynamics in learning to juggle. Motor Control, 8, 188-212.

Kim, N., Growney, R., \& Turvey, M. T. (1996). Optical flow not retinal flow is the basis of wayfinding by foot. Journal of Experimental Psychology: Human Perception and Performance, 22, 1279-1288. doi: 10.1037/0096-1523.22.5.1279

Kim, N., Turvey, M. T., \& Growney, R. (1996). Wayfinding and the sampling of optical flow by eye movements. Journal of Experimental Psychology: Human Perception and Performance, 22, 1314-1319. doi: 10.1037/0096-1523.22.5.1314

Lee, D. N. (1998). Guiding movement by coupling taus. Ecological Psychology, 10, 221-250.

Lee, D. N. (2009). General tau theory: Evolution to date. Perception, 38, 837-858.

Livingstone, M., \& Hubel, D. (1988). Segregation of form, color, movement, and depth: Anatomy, physiology, and perception. Science, 240, 740-749. doi: 10.1126/science.3283936

Milner, A. D., \& Goodale, M. A. (1995). The visual brain in action. Oxford, UK: Oxford University Press. 
Milner, A. D., \& Goodale, M. A. (2008). Two visual systems reviewed. Neuropsychologia, 46, 774-785.

Rodrigues, S. T., Aguiar, S. A., Polastri, P. F., Godoi, D., Moraes, R., \& Barela, J. A. (2013). Effects of saccadic eye movements on postural control stabilization. Motriz: Revista de Educação Física, 19, 614-619.

Rodrigues, S. T., Polastri, P. F., Carvalho, J. C., Barela, J. A., Moraes, R., \& Barbieri, F. A. (2015). Saccadic and smooth pursuit eye movements attenuate postural sway similarly. Neuroscience Letters, 584, 292-295.

Rodrigues, S. T., Polastri, P. F., Gotardi, G. C., Aguiar, S. A., Mesaros, M. R., Pestana, M. B., \& Barbieri, F. A. (2016). Postural control during cascade ball juggling: Effects of expertise and base of support. Perceptual \& Motor Skills, 123, 279-294.

Rodrigues, S. T., Vickers, J. N., \& Williams, A. M. (2002). Head, eye and arm coordination in table tennis. Journal of Sports Sciences, 20, 187-200.

Savelsbergh, G. J. P., Haans, S. H. A., Kooijman, M. K., \& van Kampen, P. M. (2010). A method to identify talent: Visual search and locomotion behavior in young football players. Human Movement Science, 29, 764-776.

Savelsbergh, G. J. P., Onrust, M., Rouwenhorst, A., \& van der Kamp, J. (2006). Visual search and locomotion behaviour in a four-tofour football tactical position game. International Journal of Sports Psychology, 37, 248-265.

Savelsbergh, G. J. P., \& van der Kamp, J. (2000). Information in learning to coordinate and control movements: Is there a need for specificity of practice? International Journal of Sports Psychology, 31, 476-484.

Schneider, G. E. (1969). Two visual systems. Science, 163, 895-902. doi: $10.1126 /$ science. 163.3870 .895

Trevarthen, C. B. (1968). Two mechanisms of vision in primates. Psychologische Forschung, 31, 299-337. doi: 10.1007/BF00422717

Ungerleider, L. G., \& Mishkin, M. (1982). Two cortical visual systems. In D. J. Ingle, M. A. Goodale, \& R. J. W. Mansfield (Eds.), Analysis of visual behaviour (pp. 549-586). Cambridge, MA: MIT.

Vickers, J. N. (1996). Visual control when aiming at a far target. Journal of Experimental Psychology. Human Perception and Performance, 22, 342-354.

Vickers, J. N. (2016). Origins and current issues in Quiet Eye research. Current Issues in Sport Science, 1:101. doi: 10.15203/ CISS_2016.101 